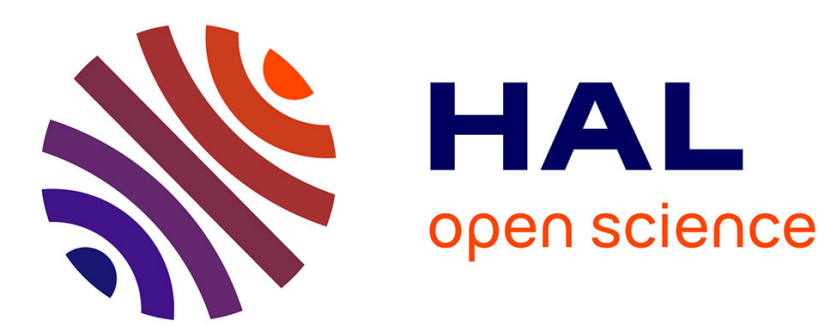

\title{
A miniature silicon hot wire sensor for automatic wind speed measurements
}

Mourad Laghrouche, Abd El Hamid Adane, Jumana Boussey-Said, Soltane Ameur, David Meunier, Sedat F. Tardu

\section{- To cite this version:}

Mourad Laghrouche, Abd El Hamid Adane, Jumana Boussey-Said, Soltane Ameur, David Meunier, et al. A miniature silicon hot wire sensor for automatic wind speed measurements. Renewable Energy, 2005, 30, pp.1881-1896. 10.1016/j.renene.2004.12.005 . hal-00262013

\section{HAL Id: hal-00262013 \\ https://hal.science/hal-00262013}

Submitted on 11 Feb 2020

HAL is a multi-disciplinary open access archive for the deposit and dissemination of scientific research documents, whether they are published or not. The documents may come from teaching and research institutions in France or abroad, or from public or private research centers.
L'archive ouverte pluridisciplinaire HAL, est destinée au dépôt et à la diffusion de documents scientifiques de niveau recherche, publiés ou non, émanant des établissements d'enseignement et de recherche français ou étrangers, des laboratoires publics ou privés. 


\title{
A miniature silicon hot wire sensor for automatic wind speed measurements
}

\author{
M. Laghrouche ${ }^{\mathrm{a}}$, A. Adane ${ }^{\mathrm{b}, *}, \mathrm{~J}_{\text {. Boussey }}^{\mathrm{c}}, \mathrm{S}$. Ameur $^{\mathrm{a}}$, \\ D. Meunier ${ }^{\mathrm{c}}, \mathrm{S}$. Tardu ${ }^{\mathrm{d}}$

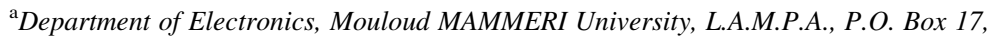 \\ RP 15000 Tizi Ouzou, Algeria \\ ${ }^{\mathrm{b}}$ Faculty of Electronics and Computer Science, University of Sciences and Technology of Algiers (U.S.T.H.B.), \\ P.O. Box 32 El Alia, Bab Ezzouar, Algiers, Algeria \\ ${ }^{\mathrm{c}}$ Institute of Microelectronics, Electromagnetism and Photonics IMEP, \\ ENSERG, 23 rue des Martyrs, 38016 Grenoble cedex 1, France \\ ${ }^{\mathrm{d}}$ Laboratoire des Ecoulements Géophysiques et Industriels, LEGI, \\ INPG-UJF-CNRS B.P. 53 X, 38402 Grenoble cedex, France
}

In order to make air flow measurements easier and more accurate, a very small sensor has been constructed. The fabrication of such a sensor mainly consists in depositing a thin doped polycrystalline silicon layer on a $4^{\prime \prime}$ silicon wafer by using a silicon-micromachined technique. At the end of the integration process, the wafer is sliced into 46 wind sensors. Each of them comprises a polycrystalline silicon layer which is $0.5 \mu \mathrm{m}$ thick, with width running from 2 to $5 \mu \mathrm{m}$ and length, from 45 to $58 \mu \mathrm{m}$. Supplied with a dc electrical current, each layer acts as a hot wire on contact with the fluid under study. Wind speed is then measured by detecting the resistance variations caused by the thermal transfer from the heated layer to the ambient atmosphere. A microcontroller-based data acquisition system has especially been designed so as to collect the wind speed measurements arising from this kind of hot wire transducer. The integrated silicon sensors have been experimented within a wind tunnel and calibrated for air speed ranging from 0 to $35 \mathrm{~m} / \mathrm{s}$. Initially intended for wall shear stress monitoring, these sensors can usefully be employed as anemometers for wind energy applications.

\footnotetext{
* Corresponding author.

E-mail address: tirgedz@yahoo.fr (A. Adane).
}

0960-1481/\$ - see front matter (C) 2005 Elsevier Ltd. All rights reserved. doi:10.1016/j.renene.2004.12.005 


\section{Introduction}

It is well known that wind speed measurements are essential to various domains such as aeronautics, meteorology, energy conversion, architecture, sealing and farming [1-9]. To perform such measurements, several types of sensors and devices are available in the market. These are on one hand, propeller, cup, ultrasonic, pressure plate, pressure tube and hot wire anemometers $[3,4,10]$, and on the other hand, electromagnetic and acoustic radars [11-13]. The anemometers are mostly used for ground measurements and radars, for wind profile observations. Propeller and cup anemometers are most commonly employed in the meteorological stations and airports. They are equipped with a dc generator, which converts wind speed into electric current. Such transducers are robust but their dc generator must be regularly maintained. The pressure plate and tube anemometers are based on the measurement of air pressure and its proportionality to the square of wind speed. The pressure plate or normal plate is the oldest but simplest sensor. Its response time is very short $(\sim 0.01 \mathrm{~s})$. The pressure tube also called Pitot tube, yields very accurate wind speed data. It is then considered as the standard in wind tunnel tests. However, this sensor is not suitable for wind measurements in wet atmosphere since the tube is sometimes sealed by the dump of dust, water droplets and ice crystals. The ultrasonic anemometer is composed of three ultrasonic transducers placed following a fixed triangular layout. Each transducer alternately acts as ultrasonic emitter and receiver. Ultrasonic pulses are then generated and propagate from a transducer to another. After, the role of the transducers is exchanged and the resulting pulses follow the opposite way. Wind speed is finally deduced from the measurements of the transit time of the pulses in the direct and inverse directions. Such an anemometer is proper to surface wind measurements. The hot wire anemometer consists in measuring the resistance variations of an electric conductor crossed by a dc current and cooled by wind. In most cases, it is mostly employed for wind shear stress measurements [14-21]. The wire of this sensor was initially made of platinum or compounds of platinum and tungsten. Therefore, such a transducer must be heated at high temperature $\left(\sim 1000{ }^{\circ} \mathrm{C}\right)$. It is well adapted to the measurement of wind speed in the range running from 0.05 to $10 \mathrm{~m} / \mathrm{s}$. However, it is fragile and consumes an important electric power. Another sort of hot wire is the thermistor. Essentially made of doped silicon semiconductor, it can work as anemometer at lower temperature $\left(\sim 100^{\circ} \mathrm{C}\right)$. It is much more robust and spends weaker electric power. However, it responds slowly to wind speed variations. The atmosphere is generally investigated at different altitudes by electromagnetic radars working at high frequencies such as VHF, UHF, microwave, infrared and optical frequencies [11,12]. Briefly, the pulsed electromagnetic waves emitted by radar, intercept atmospheric targets. Next, the waves backscattered by these targets, are received by the radar and processed so as to get the features of the observed targets. In particular, wind speed measurements are performed by detecting the Doppler frequency characterising the motion of air particles in the atmosphere. Radars operating in the VHF and UHF ranges are essentially employed as wind profilers since they can detect the vertical wind component against altitude especially under clear sky conditions. Such wind profilers are of two sorts, respectively called ST (Stratosphere-Troposphere) and MST (Mesosphere-Stratosphere-Troposphere) radars. The microwave radars installed in the meteorological stations, are generally used to 
observe scattering targets in the troposphere, namely precipitation fields, clouds and refractive index variations caused by air circulation. Several of them, called Doppler radars, are especially designed to get wind speed measurements. They are based on the production of coherent pulses and the extraction of the frequency Doppler of the moving atmospheric particles from the resulting radar echoes. The radars working in optical and infrared ranges are called lidars. They are suitable to the observation of atmospheric aerosols in the lower atmosphere. This region of atmosphere can also be probed by means of acoustic radars or sodars [13]. The latter consist in emitting sound waves and processing the arising acoustic radar echoes with the help of the same techniques as those used for lidar observations. Owing to the atmospheric absorption, sodars can measure wind speed only from 0 to about $0.5 \mathrm{~km}$ of altitude and are unable to observe precipitation fields and high winds. To get wind profiles, tethered or free balloons tracking appropriate meteorological sensors and electronic instrumentation, can be utilised [22]. The major disadvantages of balloons are their inability to perform wind measurements simultaneously at all altitudes and continuously in time. An alternative method is the use of a vertical mast where same anemometers are placed at different altitudes. However, the measurement of the three wind speed components at various altitudes needs the utilisation of many identical sensors. In the case of wind energy conversion, wind turbines producing electricity, are mounted at the top of towers of several $10 \mathrm{~m}$ of height. The tower height is usually fixed following the technical specifications of the manufacturer. In fact, to find the best sites and heights where wind turbines have to be installed, it is very important to get accurate wind speed data, in space and in time, from the ground till to about $50 \mathrm{~m}$ of altitude. A mast of $50 \mathrm{~m}$ of height equipped with appropriate wind sensors, seems to be the best way for collecting wind data at very low altitudes and evaluating wind energy resources in the region under consideration. To make such measurements easier, all these sensors must have the same response and be monitored by an automatic data acquisition system. In these conditions, a very small hot wire sensor has been constructed using integrated silicon-based technologies. This kind of transducer has been chosen since it is well adapted to both wind tunnel and mast measurements. The principal steps of the fabrication of this sensor and the different tests made in our Laboratory, are presented hereafter. A wind data acquisition system where several miniature hot wire sensors are taken as input, is also described in this article.

\section{The hot wire sensor}

\subsection{Design}

As shown in Fig. 1, the hot wire sensor under study is made of a thin polycrystalline silicon film, two metallic electrodes and a substrate. Surrounded by ambient air at temperature $\left(T_{\mathrm{a}}\right)$, the silicon film is crossed by a dc current $(I)$ which heats it at temperature $(T)$. As air blows on the hot wire, air cooling causes resistance variations which are detected so as to make wind speed measurements possible. The silicon film is a parallelepiped of $(d)$ length, $(w)$ width and $(h)$ thickness. A small cavity lying below the sensor acts as a black body. As illustrated in Fig. 1a, air then flows along the upper face 


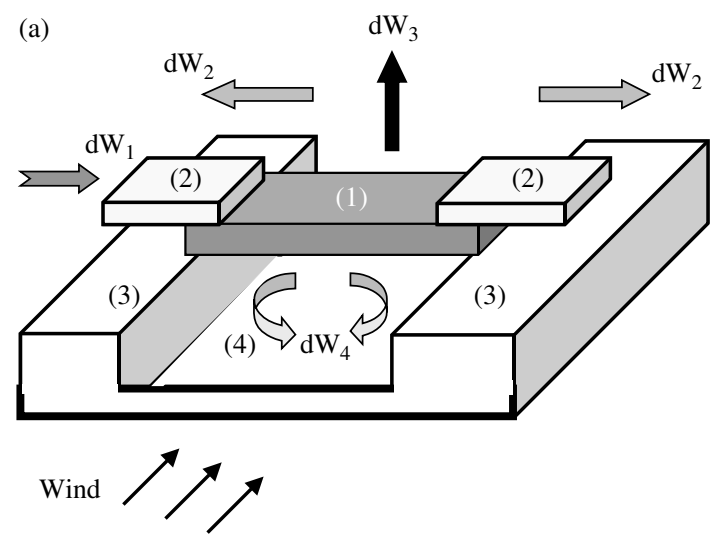

(b)

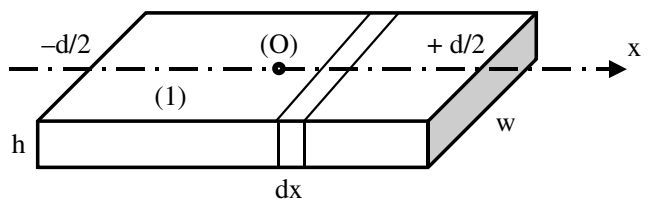

Fig. 1. Description of a hot wire transducer, where (1) labels the hot wire, (2) its electrodes, (3) its substrate and (4) the cavity beneath. (a) Thermal exchanges in the hot wire. (b) Decomposition into infinitesimal layers.

whereas the air circulation is turbulent under the lower face. To evaluate the hot wire temperature, the origin of $x$ axis is taken at the centre of the silicon film and the latter is decomposed into infinitesimal layers of length $(\mathrm{d} x)$ and cross section $(S)$ (see Fig. 1b). Let $R$ be the resistance of the sensor, $\lambda$, its thermal conductivity and $\theta=T-T_{\mathrm{a}}$, the temperature deviation. Each infinitesimal layer receives electric energy $\left(\mathrm{d} W_{1}\right)$ and energy $\left(\mathrm{d} W_{2}\right)$ due to thermal conduction, written as: $\mathrm{d} W_{1}=\frac{R}{d} I^{2} \mathrm{~d} x \mathrm{~d} t$ and $\mathrm{d} W_{2}=\lambda S \frac{\partial^{2} \theta}{\partial x^{2}} \mathrm{~d} x \mathrm{~d} t$. Owing to air convection, thermal energy amounts $\left(\mathrm{d} W_{3}\right)$ and $\left(\mathrm{d} W_{4}\right)$ leave the upper and lower faces, respectively. They are expressed as: $\mathrm{d} W_{3}=\theta U(v) w \mathrm{~d} x \mathrm{~d} t$ and $\mathrm{d} W_{4}=\theta \kappa w \mathrm{~d} x \mathrm{~d} t$, where $\kappa$ is the emissivity of the polycrystalline silicon material and $U(v)$ is a function deduced from the King relationship, given by [14-17]:

$$
U(v)=a+b v^{1 / 2}
$$

In practice, $a$ and $b$ coefficients are evaluated empirically from the current-voltage and resistance-temperature curves of the sensor under study. The heat transfer equation of the hot wire is then written as:

$$
\frac{\partial^{2} \theta}{\partial x^{2}}-\frac{w}{\lambda S}[U(v)+\kappa] \theta=\frac{\rho C_{\mathrm{p}}}{\lambda} \frac{\partial \theta}{\partial t}-\frac{R I^{2}}{\lambda S d}
$$

In this equation, $\rho$ and $C_{\mathrm{p}}$ are the density and specific heat of the polycrystalline silicon material, respectively. Taking into account that the electrodes are nearly at ambient temperature $\left(T_{\mathrm{a}}\right)$, the limit conditions are: $\theta=0$ for $x=-d / 2$ or $+d / 2$. At the steady state, the first term of the right hand side vanishes. Since the small cavity reduces the emissivity 
of the silicon film strongly, $\kappa$ can be neglected and the resolution of Eq. (2) yields:

$$
\theta=\frac{R I^{2} \ell^{2}}{\lambda S d}\left[1-\frac{\cos h \frac{x}{d}}{\cos h \frac{d}{2 \ell}}\right]
$$

with:

$$
\ell \approx\left[\frac{\lambda h}{U(v)}\right]^{1 / 2}
$$

Integrating $\theta(x)$ from $-d / 2$ to $+d / 2$, we get the temperature average of the hot wire sensor:

$$
\bar{\theta}=\frac{R I^{2}}{w\left(a+b v^{1 / 2}\right)}\left[1-\frac{2}{d}\left(\frac{\lambda h}{a+b v^{1 / 2}}\right)^{1 / 2} \tan h\left(\frac{d}{2}\left(\frac{a+b v^{1 / 2}}{\lambda h}\right)^{1 / 2}\right)\right]
$$

Let $\alpha$ be the temperature coefficient of the resistance of the hot wire sensor and $R_{\mathrm{a}}$, its resistance at ambient temperature. At temperature $T$, the sensor resistance is given by:

$$
R=R_{\mathrm{a}}\left[1+\alpha\left(T-T_{\mathrm{a}}\right)\right]
$$

with $\alpha=\frac{1}{R_{0}} \frac{\partial R}{\partial T}$ (where $R_{0}$ is the resistance at $0{ }^{\circ} \mathrm{C}$ ).

Taking into account Eq. (6), the relationship (5) means that the measurement of wind speed depends on both the variations of electric current and temperature [15]. Two sorts of methods of measurement can then be considered. The first method consists in using the electronic circuit of Fig. 2 to supply the hot wire sensor with a constant current. The second one is based on the regulation of the sensor temperature by means of the electronic

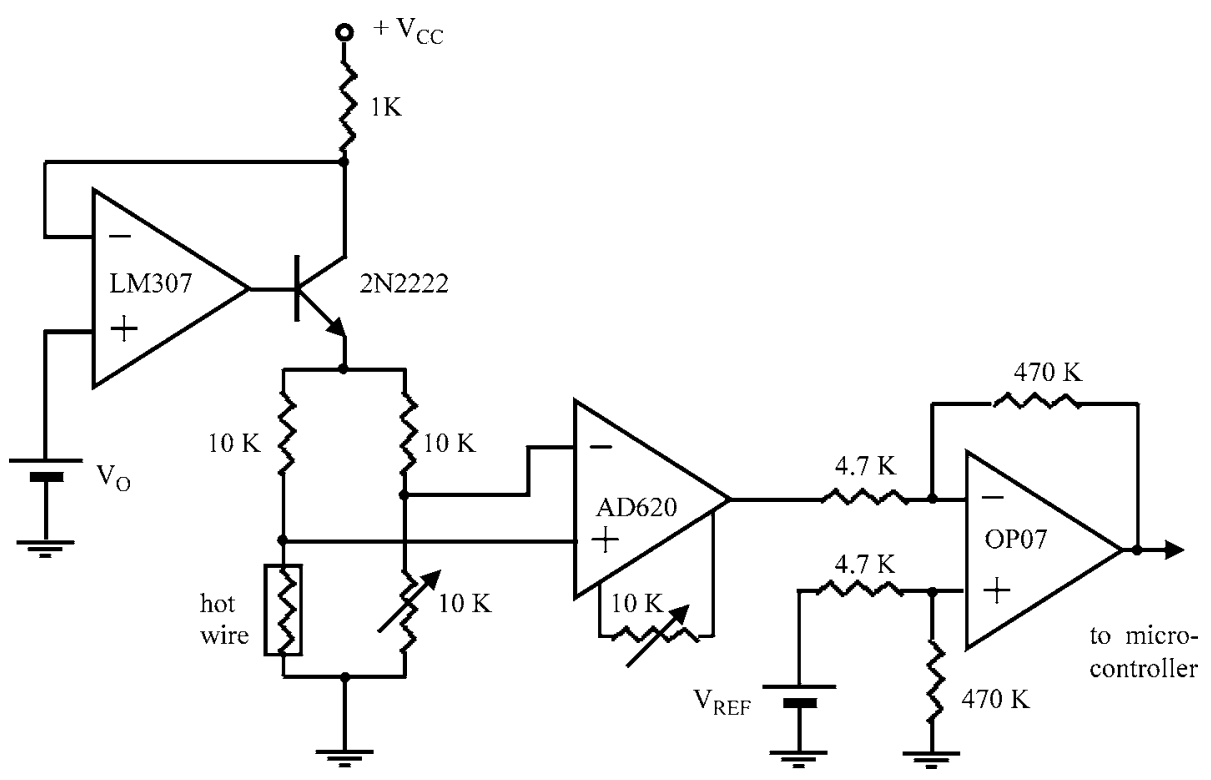

Fig. 2. Electronic circuit supplying the hot wire sensor with constant current. 


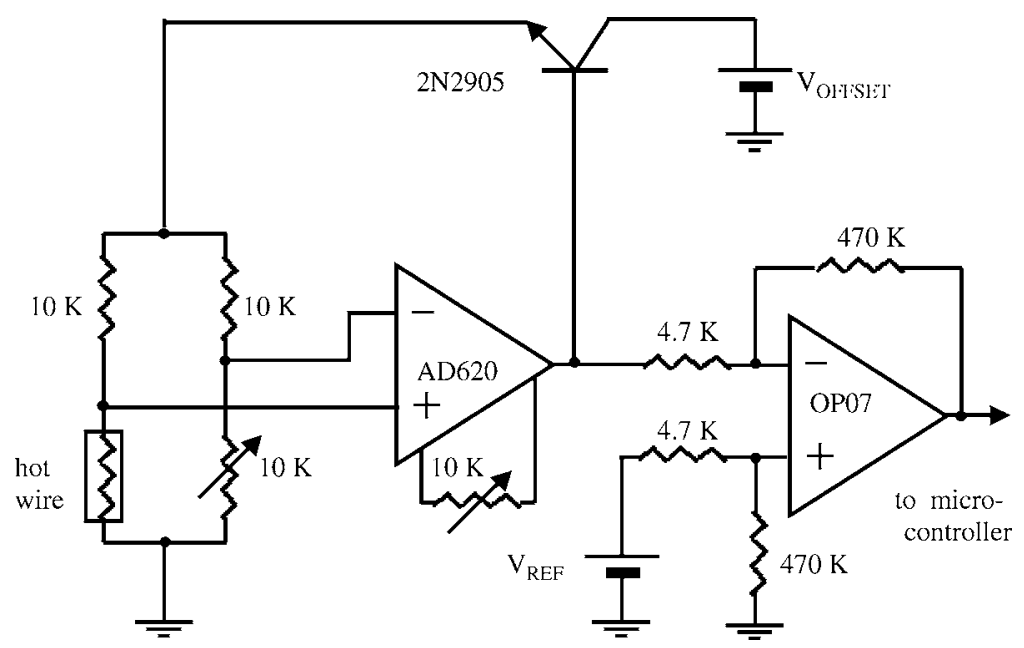

Fig. 3. Electronic circuit for the regulation of the sensor temperature.

circuit of Fig. 3. Both the devices include a Wheatstone bridge, an AD620 operational amplifier and an OP07 differential amplifier. The Wheatstone bridge consists of the hot wire anemometer, two identical resistance of $0.01 \%$ of accuracy and a tuneable resistance. The Wheatstone bridge of the device of Fig. 2 is fed by a constant current source made of a 2 N2222 transistor and an LM307 operational amplifier whereas the device of Fig. 3 is equipped with an offset compensation network built with a 2905 transistor. The dc voltages used are $\mathrm{V}_{0}=+5 \mathrm{~V}, \mathrm{~V}_{\mathrm{CC}}=+12 \mathrm{~V}, 0 \leq \mathrm{V}_{\mathrm{REF}} \leq+5 \mathrm{~V}$ and $0 \leq \mathrm{V}_{\text {OFFSET }} \leq+$ $12 \mathrm{~V}$. The working conditions of both electronic circuits are uneasy to analyse when employing the relationship (5). To estimate the hot wire sensor temperature more simply, it suffices to neglect the first term of the left hand side of Eq. (2). In this case, it is found that:

$$
P=R I^{2} \approx U(v) A\left(T-T_{\mathrm{a}}\right)
$$

with $A=w d$ and $T-T_{\mathrm{a}}=\bar{\theta}$.

In Fig. 2, the feedback loop operates in the circuit so that the current is kept constant. The output voltage of this circuit is then proportional to $U(v)$. It is written as:

$$
E=C_{1}+C_{2} v^{1 / 2}
$$

where $C_{1}$ and $C_{2}$ are calibration coefficients.

In the electronic circuit of Fig. 3, the role of the feedback loop is to make the hot wire temperature constant by varying the current through the sensor. The electric power collected at the output of this circuit is then:

$$
P=\frac{E^{2}}{R}=D_{1}+D_{2} v^{1 / 2}
$$

where $D_{1}$ and $D_{2}$ are calibration coefficients. 
The electronic circuit of Fig. 2 has the property of working with constant electric power whereas the electronic circuit of Fig. 3 has the advantage of reducing the thermal inertia of the hot wire significantly. In this case, the response time of this sensor becomes very short.

\subsection{Fabrication}

The fabrication of a single hot wire sensor consists of seven principal steps illustrated by Figs. 4-6. The resulting microelectronic component has been implemented using techniques based on the micro-electromechanical system (MEMS) [20,21,23,24]. At the beginning of the process, a monocrystalline silicon wafer of $4^{\prime \prime}$ of diameter is used as substrate. As shown in Fig. 4a, the first step consists in depositing a silicon nitride layer on this sample by means of Plasma Enhanced Chemical Vapour Deposition technique (PECVD). A layer of $0.3 \mu \mathrm{m}$ thick is then obtained. In the second step, the silicon nitride material is recovered by an appropriate mask (mask 1 of Fig. 4b). It is then treated by photolithography and the non masked part of the film is removed using SF6 plasma etching (see Fig. 4c). This yields a $50 \times 30 \mu \mathrm{m}^{2}$ window in the silicon nitride layer. As shown in Fig. $4 d$, the third step is the growing of the silicon oxide within this window. It consists in oxidising the silicon substrate underlying the window under wet ambient and high temperature conditions. The oxidation parameters have been previously adjusted using

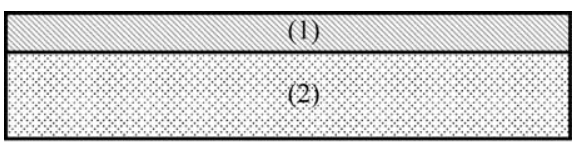

(a)

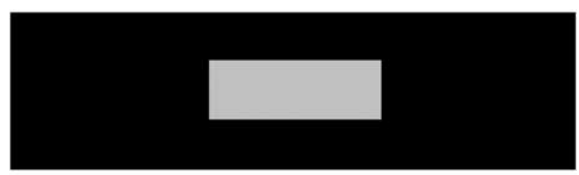

(b)

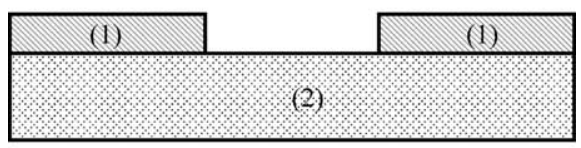

(c)

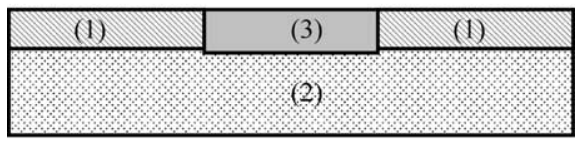

(d)

Fig. 4. Fabrication steps of a polycrystalline silicon wind sensor, where (1) labels the silicon substrate, (2) the silicon nitride film and (3) the silicon oxide (continued). (a) Deposition of a silicon nitride layer of $0.3 \mu \mathrm{m}$ of thickness. (b) Mask 1. (c) Windows patterning. (d) Oxidation of the silicon substrate. 


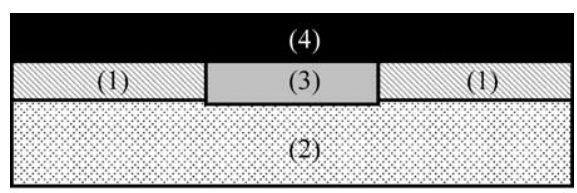

(a)

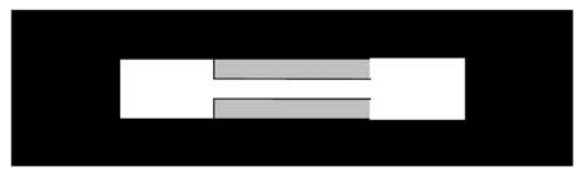

(b)

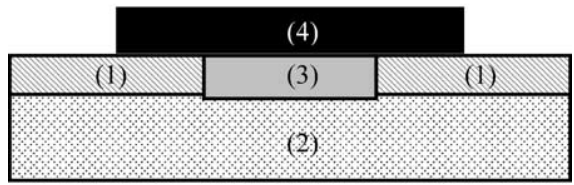

(c)

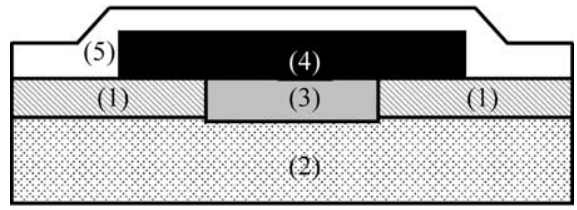

(d)

Fig. 5. Fabrication steps of a polycrystalline silicon wind sensor, where (4) labels the polycrystalline silicon film and (5), the aluminium layer (continued). (a) Deposition of polycrystalline silicon film of $0.5 \mu \mathrm{m}$ of thickness. (b) Mask 2. (c) Hot wire patterning. (d) Deposition of aluminium layer of $1.7 \mu \mathrm{m}$ of thickness.

simulation software. The resulting silicon oxide is $0.5 \mu \mathrm{m}$ thick and therefore fills the $50 \times$ $30 \mu \mathrm{m}^{2}$ window completely. Fig. 5a illustrates the fourth step where the silicon sample under study is heated at $600{ }^{\circ} \mathrm{C}$ and its upper surface is covered by a polycrystalline silicon layer of $0.5 \mu \mathrm{m}$ of thickness using the Low Pressure Chemical Vapour Deposition technique (LPCVD). The polycrystalline silicon film is then doped with a total dose of boron equalling $5 \times 10^{14}$ atoms $/ \mathrm{cm}^{2}$. For that, ion implantation of $80 \mathrm{keV}$ of energy has been employed (the ion implantation parameters were simulated before so as to get the concentration of doping molecules which maximises the thermal coefficient of the sensor). Next, the silicon sample is annealed at $1000{ }^{\circ} \mathrm{C}$ during $1 \mathrm{~h}$. Thanks to such a treatment, the doping molecules are activated and the intrinsic stress is reduced. The fifth step is the construction of the hot wire by applying another mask, called mask 2, to the polycrystalline silicon film and removing the visible part of this material with the help of reactive ion etching (see Fig. $5 b$ and c). As indicated in Fig. 5d, the sixth step is the deposition of an aluminium layer of $1.7 \mu \mathrm{m}$ of thickness at the upper surface of the silicon wafer by means of cathodic pulverisation (during this operation, chromium can also be utilized instead of aluminium). The seventh step is the elaboration of the metallic 


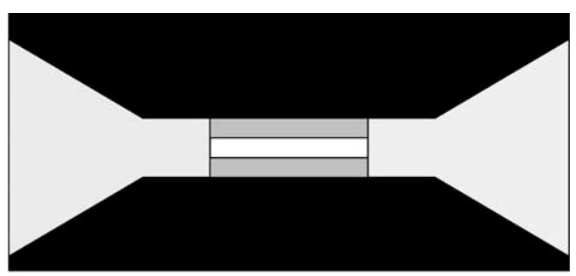

(a)

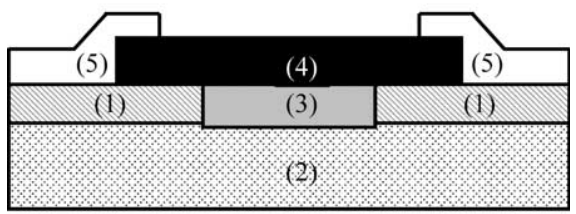

(b)

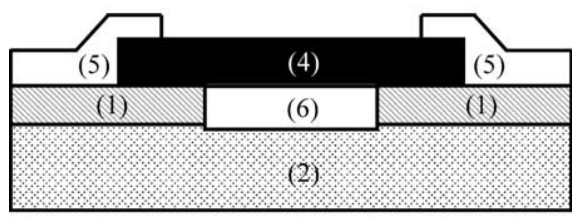

(c)

Fig. 6. Fabrication steps of a polycrystalline silicon wind sensor, where (6) labels the cavity (end). (a) Mask 3. (b) Electrode patterning. (c) Formation of the cavity below the polycrystalline silicon film.

electrodes of the hot wire by means of photolithography. The mask used in this case, is that shown in Fig. 6a (i.e. mask 3). In practice, the process described above is implemented so as to make much more than one sensor. For that, the $4^{\prime \prime}$ silicon wafer is sliced into single chips. Finally, these chips are dipped in a hydrous fluorine acid-based solution so as to remove the silicon dioxide and get a small cavity under the polycrystalline silicon film (see Fig. $6 \mathrm{~b}$ and c). In our Laboratory, 46 hot wire sensors have simultaneously been produced on the same $4^{\prime \prime}$ silicon wafer. Each of them covers a small surface which is nearly equal to $1.8 \mathrm{~cm}^{2}$. In fact, the obtained sensors can be considered as a succession of individual resistances with their section varying from $2 \times 0.5$ to $5 \times 0.5 \mu \mathrm{m}^{2}$ and their length, from 45 to $58 \mu \mathrm{m}$. Fig. 7 exhibits one of the hot wire sensors obtained at the end of the fabrication process. Finally, all these sensors are coated with an E501 epoxide liquid resin to protect them against the external atmospheric phenomena which are responsible of corrosion and oxidation.

\subsection{Indoor tests}

For each hot wire transducer, the temperature coefficient and the response time have been measured using a two-points probe station. The sensors under study have also been submitted to various tests usually performed in a wind tunnel [19,24,25]. The preliminary test is to check the linearity of the current-voltage characteristics and analyse 


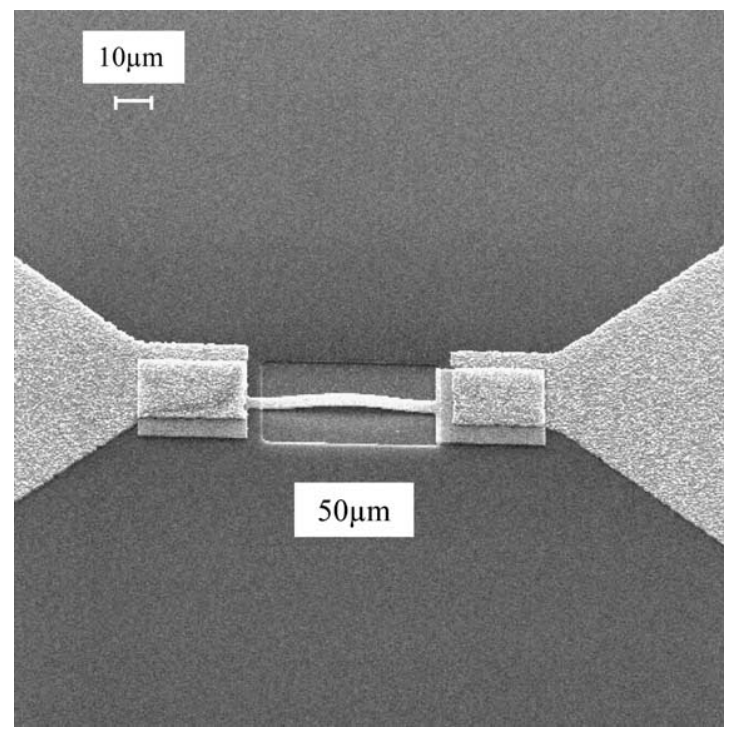

Fig. 7. Example of integrated polycrystalline silicon wind sensor.

the behaviour of the sensors with temperature. The nominal working conditions of the polycrystalline silicon layer are obtained when the current through it reaches $1 \mathrm{~mA}$ and the voltage across it lies between 5 and $10 \mathrm{~V}$. In this case, its nominal temperature is nearly equal to $70{ }^{\circ} \mathrm{C}$. The measurement of temperature coefficient consists in plotting the hot wire resistance against temperature at different positions of the two-points probe and evaluating the slope of this curve. Under the same experimental conditions, the same $\alpha$-values are obtained at any point of the upper surface of the sensors. This means that the temperature coefficient does not depend on the geometry of the hot wire resistance. As an example, Fig. 8 illustrates the $R-T$ curve obtained for a $50 \times 2 \times 0.5 \mu \mathrm{m}^{3}$ hot wire. This plot shows that the resistance variations are linear and $\alpha$ equals $-5.9 \times 10^{-4} /{ }^{\circ} \mathrm{C}$ for this sensor. This result has also been obtained for the other polycrystalline silicon transducers.

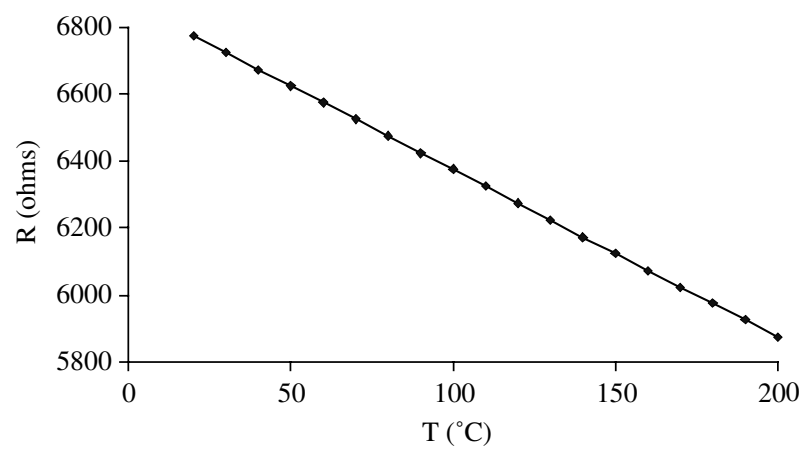

Fig. 8. Plot of resistance variations against temperature for a $50 \times 2 \times 0.5 \mu \mathrm{m}^{3}$ polycrystalline silicon wind sensor. 


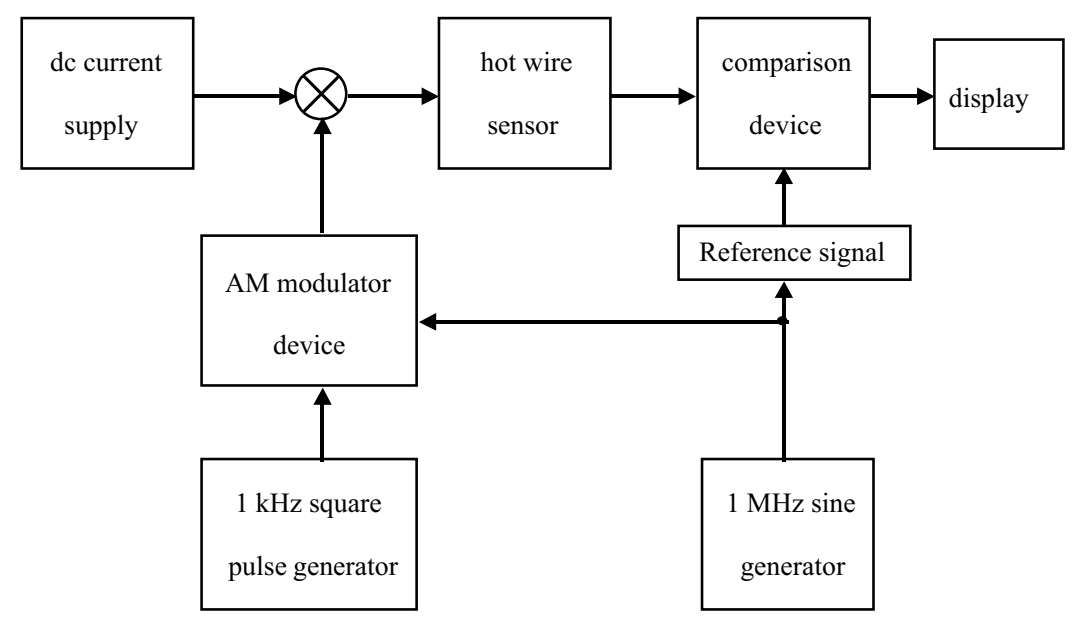

Fig. 9. Block diagram of the response time measurement system for wind hot wire transducers.

The next step is the experimental study of the speediness of the resistance variations of each sensor. The measurement circuit used is described by the scheme of Fig. 9 where the amplitude of a sine current of $1 \mathrm{MHz}$ is modulated by square pulses of $1 \mathrm{kHz}$ of frequency. The ac current so modulated is then superimposed on the dc current crossing the polycrystalline silicon film. The variations of the sensor voltage detected by the comparison device, are proportional to the temperature fluctuations, which cause the resistance variations of the hot wire. The wind sensors under study were initially constructed and then experimented without any cavity below the polycrystalline silicon layer. Table 1 gives the values of the response time obtained for some of these sensors with the help of the electronic circuit of Fig. 9. It indicates that the obtained values of response time run from 100 to $367 \mu$ s and depend strongly on the dimensions of each hot wire. The experiment has finally been conducted on other types of wind sensor, namely those where the polycrystalline silicon film has a cavity beneath. With such transducers, the response

Table 1

Response time for different polycrystalline silicon wind sensors

\begin{tabular}{llll}
\hline Size of the sensor & & \multicolumn{2}{c}{ Response time $(\mu \mathrm{s})$} \\
\cline { 1 - 2 } Length $(\mu \mathrm{m})$ & Width $(\mu \mathrm{m})$ & Thickness $(\mu \mathrm{m})$ & \\
\hline 40 & 2 & 0.5 & 100 \\
45 & 2 & 0.5 & 114 \\
50 & 2 & 0.5 & 126 \\
58 & 2 & 0.5 & 147 \\
40 & 3 & 0.5 & 172 \\
45 & 3 & 0.5 & 190 \\
50 & 3 & 0.5 & 228 \\
45 & 4 & 0.5 & 253 \\
50 & 4 & 0.5 & 367 \\
58 & 5 & 0.5 & \\
\hline
\end{tabular}


time is found to decrease 10 more times. For example, it is nearly equal to $150 \mu$ s for a $58 \times 2 \times 0.5 \mu \mathrm{m}^{3}$ hot wire without cavity whereas it is worth $15 \mu$ s with cavity. All these results are explained by the complexity of the convective and conductive heat exchanges in the vicinity of the polycrystalline silicon film, as already related in Section 2.1. Briefly, these exchanges are slowed down by the presence of the silicon substrate. The role of the cavity is to take away this substrate from the hot wire. In this case, the heat exchanges are accelerated and the response time is much more reduced. Each of the polycrystalline silicon transducers has been calibrated in terms of wind speed using the electronic circuit of Fig. 3. For that, the sensor to be calibrated and a Pitot tube are fixed together at one of the lateral walls of a wind tunnel. Another Pitot tube is placed at the centre of the wind tunnel and yields macroscopic speed measurements $\left(\nu_{\infty}\right)$ taken as reference. In Fig. 10, the output voltage of the circuit of Fig. 3 is plotted against wind speed for a $50 \times 2 \times 0.5 \mu \mathrm{m}^{3}$ hot wire with cavity, in the range running from 0 to $35 \mathrm{~m} / \mathrm{s}$. It is found that the experimental points are not fitted to Eq. (9), but they are distributed according to the following function:

$$
E^{2}=c+d \bar{v}_{\tau}^{2 n}
$$

In this equation, $c$ and $d$ are constant parameters playing the role of calibration coefficients and $\bar{v}_{\tau}$ is the friction speed of air molecules around the hot wire, measured with the help of the first Pitot tube. From the measurements collected in wind tunnel, it is deduced that: $\bar{v}_{\tau} \approx v_{\infty} / 22$. The function (10) has been adjusted to the plot of Fig. 10 by using the least-squares method. The minimum of the quadratic error of adjustment and the best fit are then obtained for $n \approx 1 / 3, c=6.132$ and $d=0.539$. The reproducibility of the sensor of Fig. 7 is also emphasized by the tests in wind tunnel. All the sensors produced following the fabrication process described in Section 2.2 and having the same dimensions, give rise to the same kind of calibration curve. In particular, among 46 wind sensors, 10 are made up of a $50 \times 2 \times 0.5 \mu \mathrm{m}^{3}$ polycrystalline silicon film with cavity. Their calibration curve is then found to be the same as that given in Fig. 10 . Another experiment is the measurement of the output voltage $(E)$ for different orientations of the polycrystalline silicon transducer with respect to wind direction. This voltage reaches its maximum when wind blows in the direction parallel to the upper face of

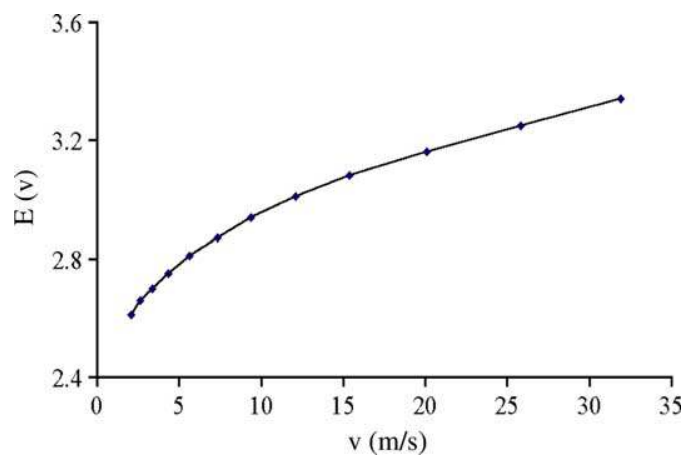

Fig. 10. Plot of output voltage against wind speed for a $50 \times 2 \times 0.5 \mu \mathrm{m}^{3}$ polycrystalline silicon wind sensor. 
the silicon substrate of the sensor under study whereas it cancels for perpendicular wind direction. Finally, a very good reliability has been shown for such a sensor after testing it in wind tunnel continuously during two days and submitting it to severe working conditions.

\section{The data acquisition system}

Several applications are based on the accurate evaluation of wind speed in space and time. For example, the design of supersonic aircrafts needs the knowledge of both the spatial distribution of wind speed and its time variations especially along the airplane wings [1,2]. In the case of wind energy applications, it is of a great importance to get the vertical wind profile in the location where the wind energy conversion systems have to be installed [4-6]. To fulfil such applications, many wind sensors must be simultaneously used and the resulting wind data, archived and processed together. These requirements can be satisfied if the wind measurements are collected with the help of the data acquisition system of Fig. 11. This system has the same general configuration as that previously used for monitoring a greenhouse in the region of Tizi Ouzou (Algeria) [26]. Its block diagram is principally composed of several input amplifiers, four 16-channel ADG406 multiplexers, a 68HC11 microcontroller and an RF transmission system. As an option, the data acquisition system is equipped with an alphanumerical display and its keyboard to check whether the microcontroller is correctly programmed or not. The $68 \mathrm{HC} 11$ microcontroller is a CMOS integrated circuit manufactured by Motorola. It is principally composed of a central processing unit (CPU), a $8 \mathrm{MHz}$ time clock, an eight-channel multiplexer, input/ output circuits (I/O), a serial interface, internal RAM (Random Access Memory) and EEPROM (Electric Erasable Programmable Read-Only Memory). It has been chosen owing to its low power consumption, its small size and its built-in analog to digital (A/D) converter. Four of the eight inputs of this converter are respectively, connected to the 16-channel multiplexers. Consequently, the data acquisition system can simultaneously receive and process 64 wind sensor signals. If necessary, the number of sensor inputs can be extended to 128 . For that, it suffices to add four other 16-channel multiplexers at the four remaining inputs of the microcontroller. The obtained data are then transferred from the microcontroller to the computer via an AM transmission system operating at $464 \mathrm{MHz}$. For that, the RF receiver is interfaced with the computer through an RS 232 serial port. The microcontroller is programmed in assembler language. The system software is organised into different subroutines, which respectively, fulfil the usual instructions of initialisation, timing and memory addressing. In accordance with the application to be implemented, the scheme of the input amplifiers is either that given in Fig. 2 or Fig. 3. Each amplifier and its wind sensor are set upon the same small printed ceramic circuit and built using the CMS technology. In the field of aeronautics, the measurements of turbulent fluxes and wind shear stress around plane wings are fundamental for the design of an aircraft [1,2]. The conditioning amplifier described in Fig. 3 is well adapted for such measurements since it reduces the response time of the hot wire significantly. In the case of wind energy applications, wind profile measurements near the ground can be performed by using several wind sensors properly distributed along a vertical mast. For example, a mast of 


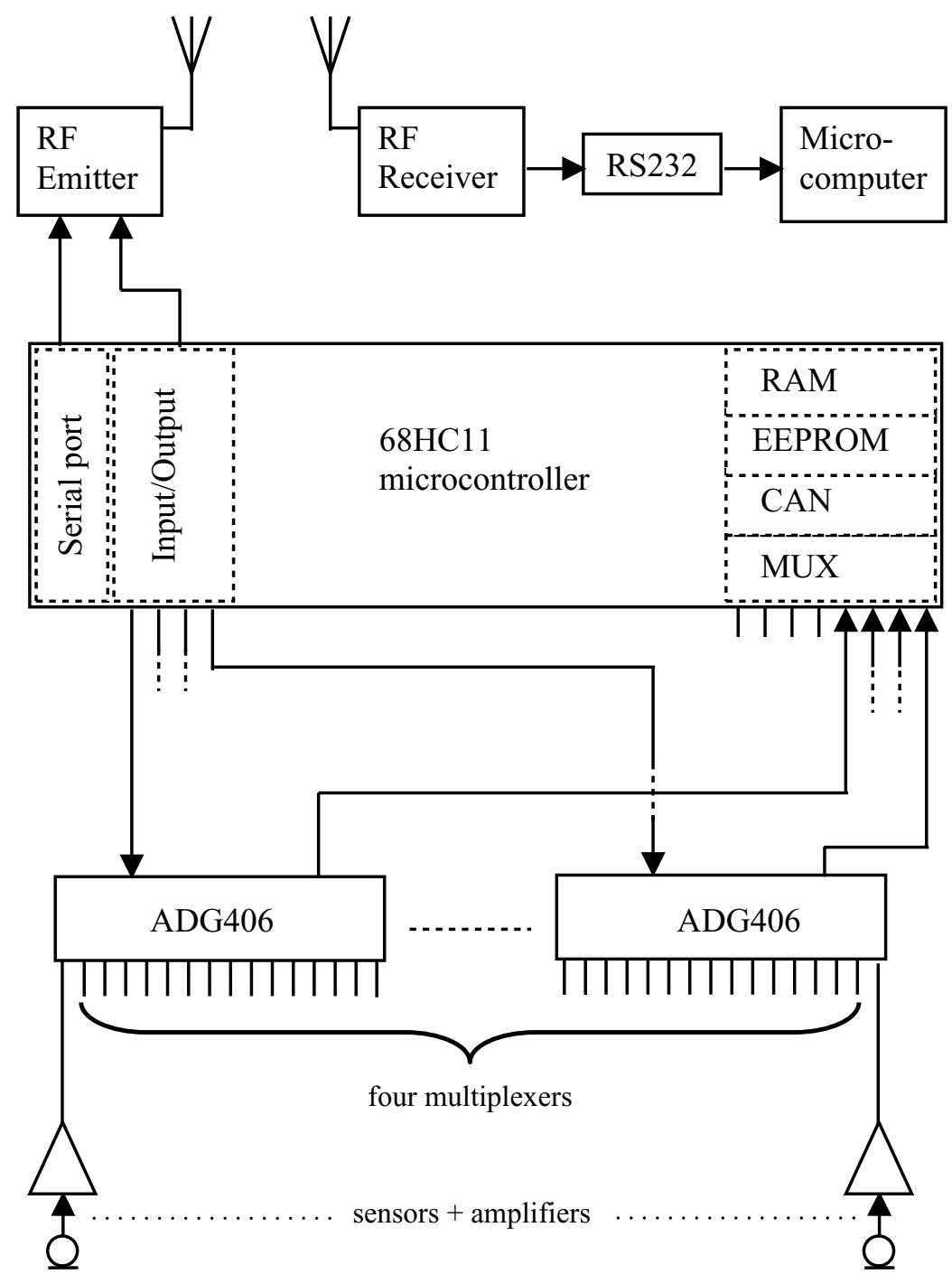

Fig. 11. Block diagram of the wind data acquisition system.

$60 \mathrm{~m}$ of length can be equipped with 60 polycrystalline silicon sensors to measure the three wind components every $3 \mathrm{~m}$. However, the most important requirement is the electric power consumed by each of these sensors. This consumption is always less than $10 \mathrm{~mW}$ per sensor. But, its fluctuations could be non negligible according to the working conditions of the sensor. The amplifier of Fig. 2 is then recommended as conditioning amplifier for this application since it has the advantage of supplying its wind sensor with constant electric power. The wind data acquisition system so described has been experimented when testing the hot wire sensors under study in the wind tunnel. During these experiments, the wind data were collected every $1 \mathrm{~ms}$ and transmitted from the wind 
tunnel to the computer by emitting only $13 \mathrm{~mW}$ of RF power. The data acquisition system has then worked very well, showing both excellent performance and no failure.

\section{Conclusions}

Thanks to the microelectronic technology, a very small wind sensor has been constructed using polycrystalline silicon material. This sensor acts as hot wire with a short response time. Owing to its smallness, it has the advantage of introducing no modification of the spatial wind distribution. As shown in Section 3, an appropriate microcontrollerbased system can be used to collect the wind data automatically and store them in a personal computer. At the input of this system, the wind signals have been previously amplified using two sorts of electronic devices. One of these devices is based on the regulation of hot wire temperature. It gives rise to a very short response time for the wind sensor under study and is suitable for the characterisation of fast air circulation, as that observed around the wings of supersonic aircraft. The other electronic circuit consists in supplying the wind sensors with constant electric current. In this case, the electric power consumed by each sensor remains constant and is lesser than $10 \mathrm{~mW}$. Such a configuration is well adapted to the applications dealing with meteorology and wind energy conversion, such as the measurement of vertical wind profiles. All these applications can be easily implemented since the wind data acquisition system possesses 64 inputs and the wind polycrystalline silicon sensors equipped with their conditioning amplifier are produced at low cost. For instance, the indoor tests performed in wind tunnel have shown that the wind sensors under study are sensitive, reproducible and reliable. However, outdoor experimentation is also needed to evaluate the long-term performance of such sensors.

\section{References}

[1] National Research Council. Low-altitude wind shear and its hazard to aviation. Washington: National Academics Press; 1983.

[2] Stengel RF. Flight dynamics. Princeton: Princeton University; 2004.

[3] Brock FV, Richardson SJ. Meteorological measurement systems. Oxford: Oxford University; 2001.

[4] Johnson GL. Wind energy systems. New Jersey: Prentice Hall; 1985. On line: www.gjohnson@ksu.edu, 2001.

[5] Manwell JF, Gowan JG, Rogers AL. Wind energy explained: theory, design and application. New York: Wiley; 2002.

[6] Burton T, Sharpe D, Jenkins N, Bossanyi E. Wind energy handbook. New York: Wiley; 2001.

[7] Dupont M, Celestine C, Feuillard T. Natural ventilation in a traditional house on a West Indies Island (Guadeloupe) field testing on site and in a wind tunnel. Renewable Energy 1994;4(3):275-82.

[8] Krokoszinski HJ. Efficiency and effectiveness of wind farms-keys to cost optimized operation and maintenance. Renewable Energy 2003;28(14):2165-78.

[9] Ikeda M, Kawakami, Seki K. A study of wind photovoltaic hybrid generation system for dairy farm efficiency of control system and annual generation results. In: Proceedings of the seventh world renewable energy congress (WREC VII). Cologne; 2002.

[10] Asch G. Les capteurs en instrumentation industrielle. Paris: Dunod; 1985.

[11] Doviak RJ, Zrnic DS. Doppler radar and weather observations. Orlando: Academic Press; 1993.

[12] Sauvageot H. Radar meteorology. Norwood: Artech House; 1992. 
[13] Neff WD, Coulter RL. Acoustic remote sensing. In: Lenschow D, editor. Probing the atmospheric boundary layer. Boston: American Meteorological Society; 1986. p. 201-66.

[14] King LV. On the convection of heat from small cylinders in a stream of fluid. Philos Trans R Soc 1914; A214:373-432.

[15] Compte-Bellot G. Hot wire anemometry: the hand book of fluid dynamics. London: RW Johnson CRC Press LLC; 1998.

[16] Lomas CG. Fundamentals of hot wire anemometry. New York: Cambridge University Press; 1986.

[17] Fingerson LM. In: Godstein RJ, editor. Thermal anemometers. New York: Hemisphere Publishing, Springer; 1983.

[18] Sheplak M, Chandrasekaran V, Cain A. Characterisation of silicon-micromachined thermal shear stress sensor. AIAA J 2002;40(6):1099-104.

[19] Liu C, Zhu Z, Tung S. A micromachined flow shear stress sensor based on thermal transfer. J Microelectromech Syst 1999;8:90-8.

[20] Kamins T. Polycrystalline silicon for integrated circuits and displays. Boston: Kluwer Academic Publishers; 1998.

[21] Ghannam MY, Dutton RW. Resistivity of boron-doped polycrystalline silicon. Appl Phys Lett 1988;52: 1222-4

[22] Morris AL, Call DE, Mc Beth RB. A small tethered balloon sounding system. Bull Am Meteorologic Soc 1975;56(9):964-9.

[23] Ho CM, Tai YC. Review: MEMS and its applications for flow control. J Fluids Eng 1996;118:437-47.

[24] Tardu S. Near wall turbulence control for local periodical blowing. Exp Thermal Fluid Sci 1998;16(1/2): 41-53.

[25] Löfdahl L. The influence of temperature on the measurements of Reynolds Stresses in shear free turbulence near a wall. Exp Fluids 1998;25:160-4.

[26] Ameur S, Laghrouche M, Adane A. Monitoring a greenhouse using a microcontroller-based meteorological data acquisition system. Renewable Energy 2001;24:19-30. 